Tohoku J. exp. Med., 1965, 86, 65-76

\title{
Ureteral Activity during Increased Intravesical Pressure
}

\author{
By
}

\author{
Seigi Tsuchida, Yukio Kimura, Takashi Someno \\ and Hiroatsu Sugawara
}

\author{
From the Department of Urology, Tohoku University School of \\ Medicine, Sendai; Director: Prof. S. Shishito
}

(Received for publication, March 4, 1965)

\begin{abstract}
Ureteral activity during the intravesical infusion was examined by urometry and electro-ureterography in 12 normal persons and a patient with vesico-ureteral reflux. The urometrograms and electro-ureterograms in normal persons indicated that when the bladder was distended with physiologic saline solution, the ureteral peristalsis responded so as to overcome the increased intravesical pressure. In the case with vesico-ureteral reflux, the ureteral peristalsis was found to be preserved. The values measured on the urometrogram and electro-ureterogram were all within the range of normal ones, and the urine was transported smoothly from the renal pelvis to the bladder without the reflux, when the intravesical pressure was below $10 \mathrm{~cm} \mathrm{H}_{2} \mathrm{O}$. When the intravesical pressure was raised up to $10 \mathrm{~cm} \mathrm{H}_{2} \mathrm{O}$, the reflux appeared. Even in this ureter persitalsis responded so as to flow out the refluxed urine. These findings suggest that ureteral perisitalis, if it remains, works to repress the veisco-ureteral reflux as far as it can resist the increased intravesical pressure and that it works against the reflux, when it actually occurs.
\end{abstract}

How the ureter responds to bladder filling is an important problem to elucidate the etiologic mechanism of the vesico-ureteral reflux. But literature dealing with the problem is scanty, for there was no adequate examination method to grasp clinical feature of the ureteral function. Direct observation of the exposed ureter, cystoscopic examination of the ureteral orifices, radiographic examination, measurement of the intraureteral pressure (hydro-phorograph) and ureteral electromyography were employed for the purpose, but information obtained with these methods was not sufficient to clarify the ureteral function.

However, in 1957, $\mathrm{Kill}^{\mathrm{l}}$ evaluated urometry in judging the functioning capacity of the ureter. On the other hand, physiologic significance of electro-ureterography was elucidated by the excellent work of Bozler. ${ }^{2}$ Nevertheless, it was far from being applied clinically, for no reliable method for non-operative installation of the electrode was introduced, and its practical value was denied by Kiil himself. Recently, ureteral action potentials were successfully recorded in our department by inserting a special electrode-catheter through a cystoscope ${ }^{3}$.

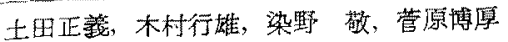


In the present study, the changes in ureteral peristalsis during intravesical infusion were observed by urometry and electro-ureterography.

\section{METHODS AND MATERIALS}

\section{Methods}

1) Preliminary experiment: In order to learn the influence on the ureteral function of the inserted urometric catheter or electromyographic catheter, indigocarmine excretion test was performed on 3 normal persons and a patient with vesico-ureteral reflux. The indigocarmine excretion from the ureteral orifice of the side under examination was observed cystoscopically before and during insertion of the catheter.

2) Urometry: Urometry was carried out by Kiil's method. In the present study, two F-5 polyethylene ureteral catheters were used; one of catheters was inserted into the ureter through a cystoscope and another into the bladder. The intraureteral pressure and intravesical pressure, which were conducted through these catheters, were recorded simultaneously with "Electronic Manometer", Mp3, connected with "4-Channel Electrocardiograph", MC-42T (Nihonkoden Co. Ltd.).

3) Electro-ureterography: Electro-ureterography was performed by the previously reported method ${ }^{3}$ using a "U-loop" collar bipolar electrode.

\section{Procedure}

Urometry and electro-ureterography were performed, while the bladder was infused with physiologic saline solution at a rate of 60 to 100 c.c. $/ \mathrm{min}$. The urine flow was controlled to be 1c.c./min by intravenous injection of the saline solution in order to keep out the influence of the change in urinary output.

In urometry, the intra-ureteral pressure was measured at intervals of $5 \mathrm{~cm}$ in the portion of the ureter between $20 \mathrm{~cm}$ and $5 \mathrm{~cm}$ from the ureteral orifice. The contraction interval was measured at $10 \mathrm{~cm}$ and intra-ureteral pressure was measured at $15 \mathrm{~cm}$ from the ureteral orifice which represents the upper portion of the ureter and at $5 \mathrm{~cm}$ which represents the lower portion. As urometry was recorded at a low speed, the contraction complexes formed a sharp spike. Accordingly, the duration was not expressed in figures.

Electro-ureterography was recorded at $10 \mathrm{~cm}$ from the ureteral orifice, for no significant difference was noted in discharge interval, amplitude, duration and propagation rate of the action potential measured between $20 \mathrm{~cm}$ and $5 \mathrm{~cm}$.

\section{Materials}

The present examination was conducted on a total of 13 subjects: 12 adults of $20-50$ years old who were urologically normal and a patient with tuberculosis of the solitary kidney in whom vesico-ureteral reflux was demonstrated. 


\section{RESULTS}

\section{Effect of inlying catheter}

As seen in Table I, insertion of urometric or electro-ureterographic catheter brought about no recognizable change in the appearance, time duration and interval of the indigocarmine excretion. From the result, it seems that the ureteral function is scarcely affected by insertion of the catheter.

TaBLE I. Infuence of Inlying Catheter on the Indigocarmino Excretion Test

1) Before Insertion

\begin{tabular}{c|cc|c|c}
\hline Case & \multicolumn{2}{|c|}{$\begin{array}{c}\text { Appearance time } \\
\text { Appearance }\end{array}$} & Duration & Interval \\
\hline 1 & $4 \mathrm{~min}$ & $55 \mathrm{sec}$ & $1 \mathrm{sec}$ & $18 \mathrm{sec}$ \\
2 & 6 & 07 & 2 & 12 \\
3 & 6 & 35 & 2 & 13 \\
4 & 8 & 54 & 3 & 28
\end{tabular}

2) During Insertion of Urometric Catheter

\begin{tabular}{l|ll|l|l}
\hline 1 & $5 \min$ & 02 sec & 1 sec & 16 sec \\
2 & 6 & 35 & 2 & 13 \\
3 & 6 & 40 & 1 & 17 \\
4 & 8 & 20 & 2 & 27
\end{tabular}

3) During Insertion of Electro-ureterographic Catheter

\begin{tabular}{l|ll|l|l}
\hline 1 & 5 min & 02 sec & 1 sec & $12 \mathrm{sec}$ \\
2 & 5 & 31 & 1 & 13 \\
3 & 6 & 32 & 2 & 13 \\
4 & 7 & 50 & 0.5 & 20
\end{tabular}

Cases $1-3$ were normal persons

Case 4 was a patient with vesico-ureteral reflux.

2. Urometrograms prior to the bladder infusion in the normal adults (Fig. 1)

Interval of consecutive contraction complexes measured in 12 cases was 16.0 to $90.7 \mathrm{sec}$ with an average of $31.6 \mathrm{sec}$, as shown in Table II. The resting pressure in these subjects was 1.5 to $13.0 \mathrm{~cm} \mathrm{H}_{2} \mathrm{O}$ with an average of $5.7 \mathrm{~cm} \mathrm{H}_{2} \mathrm{O}$ at $15 \mathrm{~cm}$ from the ureteral orifice and 0 to $18 \mathrm{~cm} \mathrm{H}_{2} \mathrm{O}$ with an average of $7.2 \mathrm{~cm} \mathrm{H}_{2} \mathrm{O}$ at $5 \mathrm{~cm}$ from the orifice (Table III). In 8 of 12 subjects, the resting pressure in the lower portion of the ureter was slightly higher than in the upper portion. The resting pressure showed no fluctuation when the bladder was empty. The contractile pressure ranged from 7.6 to $27 \mathrm{~cm} \mathrm{H}_{2} \mathrm{O}$ with an average of $13.4 \mathrm{~cm} \mathrm{H}_{2} \mathrm{O}$ at $15 \mathrm{~cm}$ from the ureteral orifice, and from 5.0 to $29.0 \mathrm{~cm} \mathrm{H}_{2} \mathrm{O}$ with an average of $17.0 \mathrm{~cm}$ $\mathrm{H}_{2} \mathrm{O}$ at $5 \mathrm{~cm}$ from the orifice. As for the contractile pressure, no considerable difference was observed between the upper and lower portions of the ureter, as seen in Table III. 


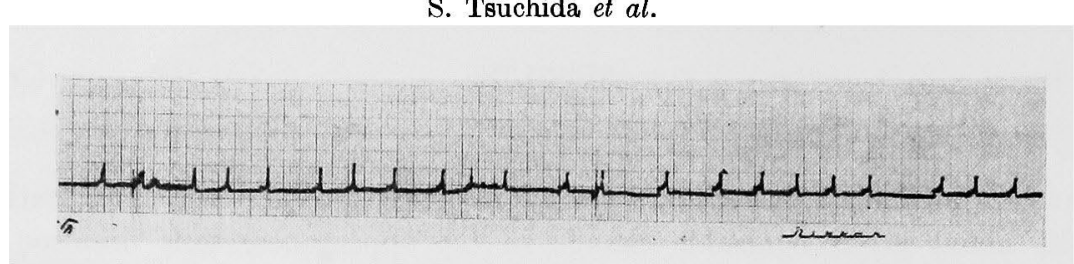

Fig. 1. Urometrogram prior to intravesical infusion.

Left normal ureter of a 21-year-old man.

The contraction interval was regular, although some difference is noted in each interval. The resting pressure and contractile pressure were nearly constant.

TABLE II. Interval of Contraction before and during Intravesical Infusion

\begin{tabular}{|c|c|c|c|c|c|}
\hline Case & Sex & Side & $\begin{array}{l}\text { Before infusion } \\
\text { (mean value) }\end{array}$ & $\begin{array}{l}\text { At filling-up } \\
\text { (minimum value) }\end{array}$ & $\begin{array}{c}\text { Rate of } \\
\text { decrease }(\%)\end{array}$ \\
\hline 1 & $\delta$ & right & $28.3 \mathrm{sec}$ & $25.0 \mathrm{sec}$ & 11.7 \\
\hline 2 & 3 & left & 20.0 & 18.0 & 10.0 \\
\hline 3 & 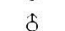 & left & 16.0 & 4.0 & 75.0 \\
\hline 4 & 古 & right & 90.7 & 64.0 & 29.4 \\
\hline 5 & $\delta$ & right & 66.7 & 44.0 & 34.0 \\
\hline 6 & \& & left & 17.9 & 7.7 & 57.0 \\
\hline 7 & $\delta$ & left & 22.8 & 13.0 & 36.0 \\
\hline 8 & $\delta$ & right & 19.0 & 13.0 & 36.8 \\
\hline 9 & \& & left & 17.8 & 18.0 & Unchanged \\
\hline 10 & $\delta$ & right & 33.8 & 18.0 & 46.7 \\
\hline 11 & q & right & 25.0 & 15.0 & 40.0 \\
\hline 12 & 今 & left & 21.5 & 17.8 & 17.2 \\
\hline \multicolumn{3}{|c|}{ Average } & 31.6 & 21.5 & 32.0 \\
\hline
\end{tabular}

3. Urometrograms during the intravesical infusion in the normal adults (Fig. 2)

When the bladder was distended to a state of repletion; that is, when the intravesical pressure was increased over 15 to $20 \mathrm{~cm} \mathrm{H}_{2} \mathrm{O}$, the intervals of the contraction became shorter (Table II). This tendency persisted for some time even after a considerable amount of the solution had been discharged from the bladder. The rate of the decrease was from 10 to $75 \%$ of the original value with an average of $32 \%$. The resting pressure increased markedly, following the increase in the intravesical pressure. The highest resting pressure in these cases was between 6.5 and $30.0 \mathrm{~cm} \mathrm{H}_{2} \mathrm{O}$ with an average of $15.4 \mathrm{~cm} \mathrm{H}_{2} \mathrm{O}$ at $15 \mathrm{~cm}$ from the ureteral orifice, and between 5.0 and $26.0 \mathrm{~cm} \mathrm{H}_{2} \mathrm{O}$ with an average of 13.8 $\mathrm{cm} \mathrm{H}_{2} \mathrm{O}$ at $5 \mathrm{~cm}$ from the orifice (Table III).

In proportion to the increase in resting pressure, the contractile pressure increased markedly in all the subjects and always exceeded the increased intravesical pressure.

The maximum contractile pressure was between 15.0 and $60.0 \mathrm{~cm} \mathrm{H}_{2} \mathrm{O}$ with an average of $26.1 \mathrm{~cm} \mathrm{H}_{2} \mathrm{O}$ at $15 \mathrm{~cm}$ from the ureteral orifice, and between 18.0 and $47.0 \mathrm{~cm} \mathrm{H}_{2} \mathrm{O}$ with an average of $30.7 \mathrm{cmH}_{2} \mathrm{O}$ at $5 \mathrm{~cm}$ from the orifice. 
TABLE III. Intraureteral Pressure before and during Intravesica] Infusion

a) Measured at $15 \mathrm{~cm}$ from the Ureteral Orifice

\begin{tabular}{r|r|r|r|r}
\hline & \multicolumn{2}{|c|}{ Before infusion } & \multicolumn{2}{|c}{ At filling-up } \\
\cline { 2 - 5 } Case & $\begin{array}{c}\text { Resting pressure } \\
\left(\mathrm{cm} \mathrm{H}_{2} \mathrm{O}\right)\end{array}$ & $\begin{array}{c}\text { Contractile } \\
\text { pressure } \\
\left(\mathrm{cmH}_{2}\right)\end{array}$ & $\begin{array}{c}\text { Resting pressure } \\
\left(\mathrm{cmH}_{2} \mathrm{O}\right)\end{array}$ & $\begin{array}{c}\text { Contractile } \\
\text { pressure } \\
\left(\mathrm{cmH}_{2} \mathrm{O}\right)\end{array}$ \\
\hline 1 & & 9.0 & 9.0 & 17.0 \\
2 & 4.0 & 19.0 & 20.0 & 28.0 \\
3 & 13.0 & 10.0 & 19.0 & 23.0 \\
4 & 8.0 & 27.0 & 12.0 & 31.0 \\
5 & 4.0 & 8.0 & 8.0 & 15.0 \\
6 & 5.0 & 15.5 & 15.0 & 25.0 \\
7 & 2.5 & 9.5 & 6.5 & 20.0 \\
8 & 4.5 & 7.6 & 11.0 & 30.0 \\
9 & 1.5 & 9.7 & 30.0 & 60.0 \\
10 & 3.0 & 9.0 & 12.5 & 15.5 \\
11 & 5.0 & 22.0 & 18.0 & 18.0 \\
12 & 6.0 & 20.0 & 24.0 & 31.0 \\
\hline Average & 12.0 & 13.4 & 15.4 & 26.1 \\
\hline
\end{tabular}

b) Measured at $5 \mathrm{~cm}$ from the Ureteral Orifice

\begin{tabular}{c|r|r|r|r}
\hline 1 & 6.0 & 15.2 & 15.0 & 25.0 \\
2 & 6.0 & 15.3 & 9.0 & 24.0 \\
3 & 4.0 & 8.0 & 11.0 & 47.0 \\
4 & 13.0 & 19.5 & 22.0 & 36.0 \\
5 & 7.5 & 17.5 & 18.0 & 29.0 \\
6 & 10.0 & 29.0 & 10.0 & 41.0 \\
7 & 0 & 5.0 & 9.0 & 22.0 \\
8 & 2.5 & 9.3 & 14.0 & 29.0 \\
9 & 8.0 & 21.6 & 5.0 & 33.0 \\
10 & 6.0 & 22.0 & 18.0 & 18.0 \\
11 & 5.0 & 13.0 & 9.0 & 32.8 \\
12 & 18.0 & 28.0 & 26.0 & 32.0 \\
\hline Average & 7.2 & 17.0 & 13.8 & 30.7
\end{tabular}

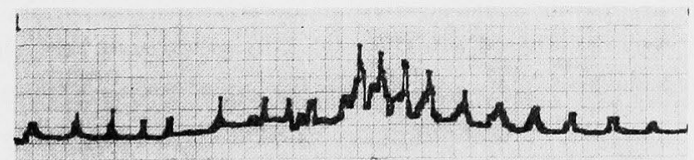

Fig. 2. Urometrogram during intravesical infusion.

Right normal ureter of a 35-year-old man.

When the intravesical pressure was caised, the intraureteral resting pressure increased almost in parallel to the intravesical pressure. When the resting pressure reached its maximum, the interval of contraction became shorter and the contraction pressure increased. The duration of a contraction also prolonged. This tendency was observed both in the upper and lower portions of the ureter, more markedly in the latter.

Tracing speed: $0.5 / \mathrm{min}$ 
As seen in Fig. 2, the duration of a contraction complex prolonged markedly, when the intravesical pressure was raised.

\section{Electro-ureterograms prior to the bladder infusion in normal adults}

When the bladder was empty, discharge interval of the action protential measured in 12 subjects was 13.9 to $40.0 \mathrm{sec}$ with an average of 21.3 sec (Table IV). The amplitude of the action potential was between 0.26 and $1.2 \mathrm{mV}$ with an average of $0.58 \mathrm{mV}$ (Table $\mathrm{V}$ ). The discharge duration was between 0.20 and 1.05 sec with an average of 0.55 sec (Table VI). The propagation rate of the action potential was between 17.5 and $66.6 \mathrm{~mm} / \mathrm{sec}$ with an average of $32.9 \mathrm{~mm} / \mathrm{sec}$, although it differed slightly in each complex (Table VII).

TABLE IV. Discharge Interval before and during

Intravesical Infusion

\begin{tabular}{r|c|c|c}
\hline Case & $\begin{array}{c}\text { Before infusion } \\
\left(\text { average value } \mathrm{cm} \mathrm{H}_{2} \mathrm{O}\right)\end{array}$ & $\begin{array}{c}\text { At filling-up } \\
\left.\text { (maximum value om } \mathrm{H}_{2} \mathrm{O}\right)\end{array}$ & $\begin{array}{c}\text { Rate of decrease } \\
(\%)\end{array}$ \\
\hline 1 & 31.6 & 13.5 & 57.2 \\
2 & 14.4 & 5.4 & 62.5 \\
3 & 13.9 & 5.3 & 61.9 \\
4 & 34.1 & 18.0 & 47.2 \\
5 & 40.0 & 7.6 & 81.0 \\
6 & 17.8 & 7.7 & 56.7 \\
7 & 17.1 & 4.1 & 76.0 \\
8 & 19.4 & 10.4 & 46.4 \\
9 & 17.7 & 14.0 & 20.9 \\
10 & 14.2 & 14.1 & 0.7 \\
11 & 20.7 & 18.0 & 13.0 \\
12 & 14.7 & 6.4 & 56.5 \\
\hline & 21.3 & 10.4 & 51.2 \\
\hline
\end{tabular}

Table V. Amplitude of Action Potential before and during Intravesical Infusion

\begin{tabular}{c|c|c}
\hline Case & $\begin{array}{c}\text { Before infusion } \\
(\mathrm{mV})\end{array}$ & $\begin{array}{c}\text { At filling-up } \\
(\mathrm{mV})\end{array}$ \\
\hline 1 & 0.47 & 0.52 \\
2 & 1.59 & 0.85 \\
3 & 1.2 & 0.73 \\
4 & 0.26 & 0.26 \\
5 & 0.29 & 0.27 \\
6 & 0.51 & 0.47 \\
7 & 0.67 & 0.53 \\
8 & 0.60 & 0.49 \\
9 & 0.72 & 0.73 \\
10 & 0.65 & 0.54 \\
11 & 0.54 & 0.53 \\
12 & 0.46 & 0.4 \\
\hline Average & 0.58 & 0.53 \\
\end{tabular}


TABLE VI. Discharge Duration before and during Intravesical Infusion

\begin{tabular}{c|c|c}
\hline Case & $\begin{array}{c}\text { Prior to bladder } \\
\text { infusion (min) }\end{array}$ & $\begin{array}{c}\text { At filling-up } \\
\text { (min) }\end{array}$ \\
\hline 1 & 0.57 & 0.50 \\
2 & 0.25 & 0.30 \\
3 & 0.93 & 1.15 \\
4 & 0.50 & 0.40 \\
5 & 0.33 & 0.45 \\
6 & 0.50 & 0.70 \\
7 & 0.75 & 0.80 \\
8 & 0.20 & 0.40 \\
9 & 0.78 & 1.05 \\
10 & 1.05 & 1.10 \\
11 & 0.40 & 0.45 \\
12 & 0.34 & 0.34 \\
\hline Average & 0.55 & 0.64 \\
\hline
\end{tabular}

Table VII. Propagation Rate of Action Potential before and during Intravesical Infusion

\begin{tabular}{r|c|c|c}
\hline Case & Before infusion & At filling-up & Rate of decrease \\
\hline 1 & 26.3 & 23.8 & 9.5 \\
2 & 66.6 & 38.5 & 42.1 \\
3 & - & - & - \\
4 & 26.3 & 21.7 & 17.5 \\
5 & 43.5 & 31.3 & 28.0 \\
6 & 32.3 & 38.6 & 11.5 \\
7 & 22.7 & 19.2 & 18.7 \\
8 & 18.7 & 27.8 & Increased \\
9 & 26.5 & 23.5 & 11.3 \\
10 & 49.2 & 17.2 & Unchanged \\
11 & 17.5 & 20.0 & 2.9 \\
12 & 33.3 & 27.3 & 39.3 \\
\hline Average & 32.9 & & 19.9 \\
& & & \\
\hline
\end{tabular}

5. Electro-ureterograms during the intravesical infusion (Fig. 3)

When the bladder was filled up, the discharge interval of the ureteral action potential shortened markedly in all the cases, as seen in Fig. 3, although the shortening rate differed slightly from case to case. The average shortening rate was $51.2 \%$ of the original value (Table IV). The amplitude of the action potential remained almost unchanged throughout the intravesical infusion (Table V). When the discharge interval shortened, the discharge duration prolonged slightly. The prolonged discharge duration ranged from 0.30 to 1.15 sec with an average of 0.64 sec (Table VI). In parallel to the shortening of the discharge interval, the propagation rate at flling-up was 17.0 to $49.2 \mathrm{~mm} / \mathrm{sec}$ (Table VII). The average decrease was $19.9 \%$ of the original value. 
Prior to infusion

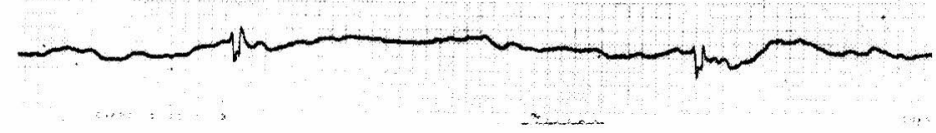

At filling-up

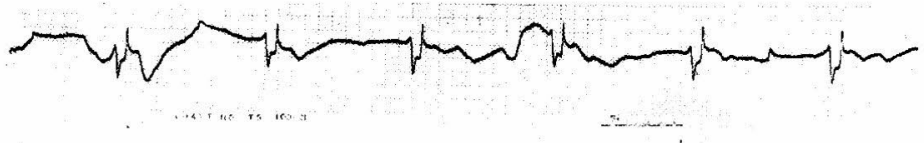

Fig. 3. Electro-ureterogram during intravesical infusion.

Left ureter of a 42-year-old man.

When the bladder was empty, the action potential measured was 34.8 sec in discharge interval, $0.80 \mathrm{mV}$ in amplitude, $0.8 \mathrm{sec}$ in discharge duration and $40.4 \mathrm{~mm} / \mathrm{sec}$ in propagation rate. When the bladder was filled up, the interval diminished to $10.8 \mathrm{sec}$ and the propagation rate delayed to $12.1 \mathrm{~mm} / \mathrm{sec}$. The amplitude remained almost unchanged, being $0.86 \mathrm{mV}$.

E.U.G. through a eystoscope using a collar bipolar electrode.

Interpolar distance: $2 \mathrm{~cm}$.

Tracing speed: $10 \mathrm{~cm} / \mathrm{sec}$.

Amplitupe: $1 \mathrm{mV}=15 \mathrm{~mm}$.

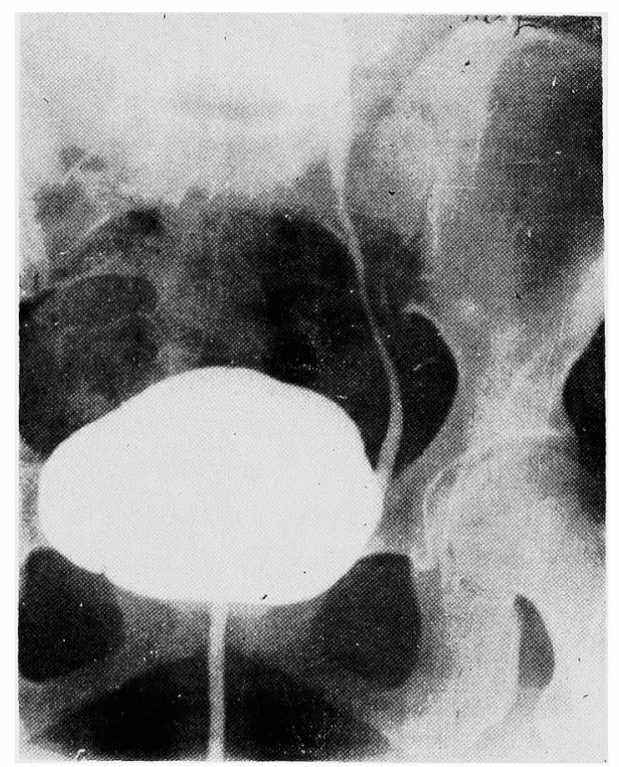

Fig. 4. Cystogram of a patient with renal tuberculosis Vesico-ureteral reflux is observed in the left ureter. 


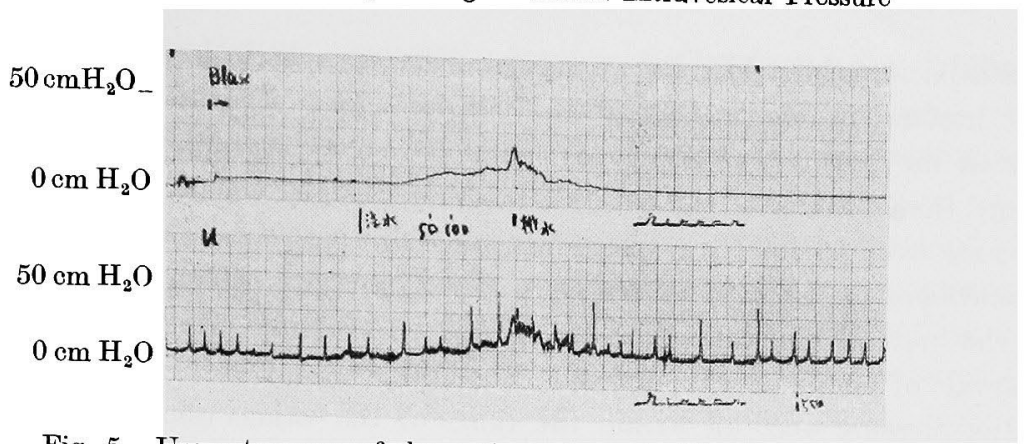

Fig. 5. Urometrogram of the patient shown in Fig. 4.

Upper tracing is the recording of the intravesical pressure and the lower tracing is that of the intraureteral pressure.

The interval of contraction ranged from 9 to $20 \mathrm{sec}$ with an average of 12 sec throughout the length of the ureter, when the bladder was empty. The resting pressure was between 3 and $6 \mathrm{~cm} \mathrm{H}_{2} \mathrm{O}$. When the bladder was fllled up, the resting pressure increased as high as $29 \mathrm{~cm} \mathrm{H}_{2} \mathrm{O}$, coinciding with the intravesical pressure and the contraction pressure increased as high as $43 \mathrm{~cm} \mathrm{H}_{2} \mathrm{O}$.

Prior to infusion

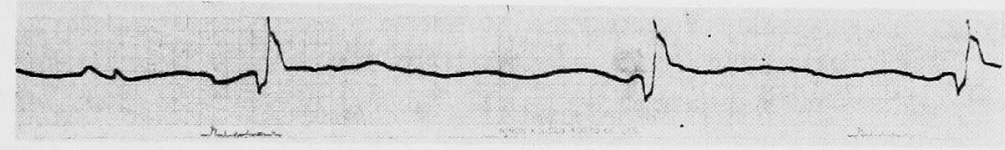

At filling-up
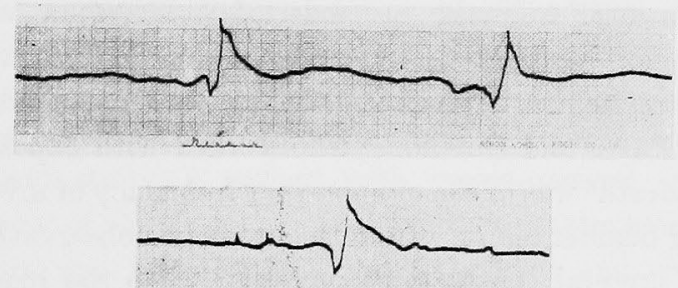

Fig. 6. Electro-ureterogram of the same patient.

When the bladder was empty, measurements of the action potential were $30.0 \mathrm{sec}$ in discharge interval, $1.7 \mathrm{sec}$ in discharge duration, $25 \mathrm{~mm} / \mathrm{sec}$ in propagation rate and $1.3 \mathrm{mV}$ in amplitued. When the bladder was filled up, the discharge interval shortened to $22.0 \mathrm{sec}$ and the discharge duration prolonged up to 1.7 sec. The propagation rate diminished to $20 \mathrm{~mm} / \mathrm{sec}$. The amplitude remained unchanged.

6. Urometrograms and electro-ureterograms in a patient with vesico-ureteral reflux

The patient underwent right nehprectomy for renal tubereulosis some years previously. The cystoscopic examination revealed that the vesical mucosa was nearly normal with a slight trabeculation. 
The capacity of the bladder was about 200 c.c., a little lower than normal. The left ureteral orifice was small and of round and depressed shape and no contraction movement was observed there. When cystography was performed with more than 100 c.c. of the contrast medium, that is, when intravesical pressure became over $10 \mathrm{~cm} \mathrm{H} \mathrm{H}_{2} \mathrm{O}$, vesico-ureteral reflux appeared (Fig. 4).

1) Urometrogram: In this ureter, pressure fluctuation which was characteristic of the ureteral peristalsis, was still preserved (Fig. 5). As shown in Fig. 5, the interval of contraction complexes, the intraureteral resting pressure and contractile pressure were all within the range of the values obtained in normal persons when the bladder was empty. When the intravesical pressure was raised, the same ureteral response was observed as in the normal subjects, except for the resting pressure. The resting pressure fluctuated coincidentally with the intravesical pressure.

2) Electro-ureterogram: The electro-ureterograms obtained with an electrode placed at $10 \mathrm{~cm}$ from the ureteral orifice are shown in Fig. 6. The ureteral electromyogram in this patient shows the same features as in the normal persons, when the bladder was either empty or filled up, but discharge duration was more prolonged in this case than in the normal subjects.

\section{DISCUSSION}

As to the ureteral response to the increased intravesical pressure, there was some disagreement among the investigators. This might be due to difference in species of experimental animals, methods of observation and experimental conditions. Pflaumer ${ }^{4}$ reported that the contraction movement of the ureteral orifices became more frequent, when the bladder was distended. Similar results were reported by Graves and Davidoff, ${ }^{5}$ who worked with exposed rabbit ureter. On the contrary, Narath ${ }^{6}$ was of the opinion that frequency of ureteral contractions was reduced during bladder filling. From the urometric observation, Kill ${ }^{1}$ reported that frequency of ureteral contractions increased when the bladder was rapidly distended. He noted further that intraureteral resting pressure increased and the duration of contraction became longer. This reaction, he pointed out, was of the same type as those encountered when the urine flow exceeded the emptying capacity of the tract. Consequently, he concluded that the reaction was not due to the vesico-ureteral reflux but to the storage of urine in the ureter. Further, Scott and De Luca ${ }^{7}$ stated that when the intravesical pressure was slightly raised, the contractile pressure of a normal canine ureter exceeded the intravesical pressure with greater frequency of the contraction. However, the resting pressure remained constant. When the intravesical pressure was raised higher, the resting pressure also increased and the contraction pressure increased more. In the present experiments, the frequency of contraction increased when the intravesical pressure was raised by the intravesical infusion. Almost in parallel to the 
increase, the resting and contractile pressure increased and the duration of the contraction prolonged. The results of the present study coincided with those reported by Kiil, and by Scott and De Luca. Further, electro-ureterography gave the results similar to those obtained by urometry: When the intravesical pressure was increased, the discharge interval of an action potential shortened markedly, discharge duration prolonged slightly, and the propagation rate lowered. Since indigocarmine excretion persists during the bladder filling, the above-mentioned change in ureteral activity observed by urometry and electro-ureterography may be regarded as a reaction to overcome the increased intravesical pressure.

As to vesico-ureteral reflux, many attempts have been made to elucidate the phenomenon from the anatomical standpoint, but there are still only a few reports dealing with the role of the ureteral function in the phenomenon. Although Tinckler ${ }^{8}$ laid a stress on the valve action in the vesico-ureteral juncture, he was of the opinion that the ureteral peristalsis itself could react against the reflux, when the valve action was insufficient. In the experiments in dogs, Scott and De Luca observed that the ureter, in which the vesico-ureteral reflux occurred, did not respond to bladder filling by an increase in contraction amplitude. When the intravesical pressure was raised up to the level of the resting pressure, the reflux, they say, occurred with disappearence of the contraction complexes. The resting pressure itself increased, taking the same pressure level as the intravesical pressure. Davis and Zimskind ${ }^{9}$ reported the result of urometry performed in 2 cases in which vesico-ureteral reflux was observed. In one of the cases the resting pressure increased mildly, following an abrupt rise of intravesical pressure and in the other case a rise in intravesical pressure was followed by a simultaneous rise in resting pressure. In none of these cases, the peristaltic movements were observed.

In the present study, a patient with vesico-ureteral reflux due to tuberculous involvement of the uretero-vesical juncture was examined. When the intravesical pressure was below $10 \mathrm{~cm} \mathrm{H}_{2} \mathrm{O}$, urometric and electro-ureterographic findings were within the rage of the normal values and vesico-ureteral reflux did not occur. Accordingly, it may be thought that the urine was smoothly transported from the renal pelvis to the bladder by ureteral peristalsis. When the bladder was filled up, the same ureteral reaction was observed as in the normal persons. The fact that the increase in the resting pressure was simultaneous with that of the intravesical pressure, seems to mean that the vesico-ureteral reflux occurred in the ureter. However, in this case the contractile pressure increased higher and discharge interval of action potential lasted longer than in the normal persons. Judging from the ureteral reaction observed in normal persons, these changes in ureteral activity can be considered as the ureteral reaction to flow out the refluxed urine again into the bladder. From these facts it is concluded that vesico-ureteral reflux dose not occur as far as ureteral peristalsis, if it is 
preserved, can overcome the increased intravesical pressure and that the ureteral peristalsis works against the reflux when it actually occurs.

Our grateful acknowledgment is made to our director, Prof. S. Shishito, for his kind guidance and careful review of the manuscript.

\section{References}

1) Kiil, F. The Function of the Ureter and Renal Pelvis, Oslo University Press, Oslo, 1957, p. 1.

2) Bozler, E. Amer. J. Physiol., 1938, 124, 502.

3) Tsuchida, S. \& Kimura, Y. Tohoku J. exp. Med., 1964, 83, 1.

4) Pflaumer, E. Z. Urol, 1919, 13, 407.

5) Graves, R.C. \& Davidoff, L.M. J. Urol., 1923, 10, 185.

6) Narath, P.A. Campbell's Urology, Vol. I, Saunders, Philadelphia, 1957, p. 61.

7) Scott, J.E.S. \& De Luca, F.G. Brit. J. Urol., 1960, 32, 216.

8) Tinckler, L.F. Proc. roy Soc. Med., 1956, 49, 702.

9) Davis, D.M. \& Zimskind, P.D. J. Urol., 1963, 90, 677. 